\title{
A MATRIZ TEÓRICA JURÍDICA DOS DESASTRES AMBIENTAIS NO CICLO DE GERAÇÃO DE ENERGIA NA SOCIEDADE SISTÊMICA ${ }^{1}$
}

\author{
Juliane Altmann Berwig ${ }^{2}$ \\ Wilson Engelmann ${ }^{3}$
}

\begin{abstract}
Resumo
A partir da Revolução Industrial, os mecanismos de produção se tornaram mais dinâmicos, automáticos, e, acompanhando estes a evolução científica incrementou novos modelos de desenvolvimento exploratório, dentre eles os mecanismos de geração de energia. Todavia, apesar das inúmeras vantagens deste novo formato de desenvolvimento, ele resulta na distribuição de riscos sistêmicos, que não distinguem limites temporais, geracionais ou territoriais e que ocasionam desastres ambientais, com consequências muito preocupantes. Estes desastres que geram danos ao meio ambiente, à comunidade, à economia, dentre outros subsistemas atingidos são desconhecidos e não são absorvidos pelo Direito, ocasionando um descontrole das operações jurídicas na contenção dos riscos de desastres. Diante disso, a partir da análise de importantes eventos catastróficos ocorridos no mundo, o presente artigo utiliza-se da pesquisa bibliográfica como metodologia, a fim de atingir seu objetivo que é compreender os desastres ambientais no ciclo de geração de energia, sua relação com a sociedade sistêmica e a imposição a readaptação do Direito voltado aos eventos futuros com fundamento na Teoria Sistêmica.
\end{abstract}

Palavras-chaves: desastres; geração de energia; risco.

\section{INTRODUÇÃO}

O rompimento da barragem em Mariana/MG teve consequências ambientais e sociais lamentáveis decorrentes do despejo não premeditado de lama, desde as diversas famílias que perderam as suas casas e entes queridos até expressivos e irrecuperáveis danos a fauna e a flora. A Samarco, responsável pelo empreendimento de

\footnotetext{
${ }^{1}$ Resultado parcial do projeto de pesquisa desenvolvido pelos autores intitulado: "As transformações jurídicas das relações privadas: a construção de marcos regulatórios e a revisão de categorias tradicionais do Direito como condição de possibilidade para atender aos desafios das mutações jurídicas contemporâneas geradas pelas novas tecnologias" (UNISINOS). Além das discussões realizadas no âmbito do Grupo de Pesquisa JUSNANO/CNPq.

${ }^{2}$ Mestre em Direito pela Universidade do Vale do Rio dos Sinos, especialista em Direito Ambiental Nacional e Internacional pela Universidade Federal do Estado do Rio Grande do Sul. Integrante da Diretoria de Grupos de Estudos da Associação Gaúcha dos Advogados do Direito Imobiliário Empresarial-AGADIE e Vice-Presidente do Movimento Roessler para Defesa Ambiental de Novo Hamburgo/RS. . E-mail: julianeberwig@feevale.br

${ }_{3}^{3}$ Doutor em Direito Público pelo Programa de Pós-Graduação em Direito (Mestrado e Doutorado) da Universidade do Vale do Rio dos Sinos - UNISINOS/RS/Brasil. Professor deste mesmo Programa das atividades: "Transformações Jurídicas das Relações Privadas" (Mestrado) e "Os Desafios das Transformações Contemporâneas do Direito Privado" (Doutorado). Coordenador Executivo do Mestrado Profissional em Direito da Empresa e dos Negócios da Unisinos. Líder do Grupo de Pesquisa JUSNANO (CNPq).Bolsista de Produtividade em Pesquisa do CNPq. E-mail: wengelmann@unisinos.br
} 
extração e beneficiamento do minério, de propriedade da Vale S/A (50\%) e BHP Billiton Brasil Ltda. (50\%), com faturamento anual de R \$ 7,6 bilhões, foi em 2014 a 10ª maior exportadora do país. Neste empreendimento, os rejeitos são estocados em três reservatórios na mina de Mariana: Santarém, Fundão e Germano. O desastre decorreu do rompimento da barragem de rejeitos de Fundão e o galgamento da barragem de Santarém, em uma região de cabeceira da bacia hidrográfica do rio Doce. (ANA, 2015, p.21)

O desastre ambiental se sucedeu no dia 5 de novembro de 2015. O rompimento liberou um volume estimado em 34 milhões de $\mathrm{m}^{3}$ de rejeitos de mineração, água e materiais utilizados em sua construção.(IBAMA, 2015, p.2). Nos trechos a jusante, a onda resultante do rompimento da barragem avançou sobre a planície de inundação dos rios tributários, levando consigo parte da vegetação e do substrato. Esses materiais somaram-se à lama de rejeitos, agravando os danos nos trechos de cabeceira. A onda de cheia produzida a partir do rompimento da barragem de Fundão percorreu mais de $650 \mathrm{~km}$ até a foz do rio Doce, em Linhares, no litoral do Espírito Santo. (ANA, 2015, p.27)

Bento Rodrigues, subdistrito do distrito de Santa Rita Durão, município de Mariana, situado a pouco mais de $5 \mathrm{~km}$ das barragens e $35 \mathrm{~km}$ da sede de Mariana, foi praticamente todo soterrado pela avalanche de água, lama e detritos. Foram encontradas 19 vítimas fatais do acidente. No subdistrito viviam cerca de 600 habitantes. (ANA, 2015, p.23) O IBAMA estima que 207 dos 251 imóveis tenham sido destruídos naquela localidade. A alta turbidez na água causou ainda a interrupção do abastecimento de água das populações servidas pelo rio Doce nos dias seguintes ao acidente. (IBAMA, 2015, p.25)

Os principais impactos sobre os corpos hídricos e os usos da água produzidos pelo desastre foram: a interrupção do abastecimento de água em função da degradação da qualidade da água nos rios afetados; prejuízos à agricultura (irrigação); prejuízos à indústria e demais atividades econômicas que dependem da qualidade da água dos corpos hídricos atingidos; prejuízos à produção de energia nas hidrelétricas; comprometimento da pesca em toda a extensão do rio e na transição com o ambiente marinho; comprometimento do turismo, sobretudo na região do estuário do rio Doce; destruição de áreas de preservação permanente nos trechos de cabeceira; assoreamento dos corpos hídricos; alterações morfológicas dos corpos hídricos atingidos; mortandade de peixes e de outros organismos aquáticos; perturbações do equilíbrio dos ecossistemas aquáticos. (ANA, 2015, p. 30)

A qualidade da água do rio Doce estará sujeita a variações decorrentes da liberação da massa de rejeitos acumulada em sua calha quando da ocorrência de chuvas e consequente aumento da vazão, intervenções físicas abruptas no rio e outras ações antrópicas. Nesse contexto, poderão ocorrer novos picos de turbidez, queda de oxigênio dissolvido, aumento temporário da concentração de metais e prejuízos para os diversos usos de água da bacia, por períodos indeterminados e, ainda, imprevisíveis. A recuperação da qualidade das águas será, portanto, um processo longo e persistente, que deverá ser acompanhada por monitoramento quali-quantitativo consistente 
e minuciosa investigação dos vários aspectos envolvidos. (ANA, 2015, p.49)

Assim como este grave desastre que colocou a amostra a estrutura fiscalizatória e de gestão de riscos de desastres no País, diversos outros desastres ambientais antropogênicos já ocorreram no mundo. No Golfo do México milhões de litros de petróleo foram despejados no mar em 2010 com efeitos devastadores no habitat marinho além, de diversos prejuízos econômicos na pesca, no turismo e no setor imobiliário. Em 2011, Fukushima, submersa pelas ondas gigantes geradas pelo tremor de magnitude de 8.9 na escala Richter viu-se obrigada a enfrentar o inimigo invisível, a radiação, após a falha no desligamento de uma de suas usinas nucleares.

Diante destes desastres (Fukushima, Golfo do México e Mariana) e tantos outros já ocorridos, percebese que os danos decorrentes e os riscos distribuídos são muito diferentes daqueles acidentes ocorridos no início da Revolução Industrial. Neste período, os sinistros se limitavam ao local ocupado pela atividade industrial e sobre eles pairavam as responsabilidades pelos danos pretéritos. Todavia, a sociedade evoluiu e se tornou, exponencialmente, mais complexa e junto dela as novas tecnologias se desenvolveram e, apesar de resolvidos diversos problemas, criaram-se outros "desconhecidos". A estes, deram-se o nome de "riscos", que passaram a ser um componente intrínseco da sociedade pós-industrial, uma sociedade marcada pela distribuição de riquezas, mas também de muitos riscos com consequências que transcenderam os limites do imaginável, com efeitos: transtemporais, transterritoriais e transgeracionais.

Estes eventos tomam uma proporção tão imensa que à eles foi imposta a denominação de desastres. Os quais possuem uma alta energia, são multifacetados, multiníveis, complexos e prejudiciais. Além disso, seus efeitos aos sistemas relacionados se desenrolam ao longo do tempo e do espaço (SMITH, 2005, p.201-236).

Neste viés, na geração de energia, os desastres ambientais são frequentemente, consequência das fontes não renováveis, possuindo drásticas e, por vezes, irreversíveis consequências. Logo, estes eventos desafiam respostas antecipadas do Direito fundamentadas nos princípios da prevenção e precaução, a fim de conter ao máximo o risco de desastres e, na sua ocorrência introduzir mecanismos de contenção de danos.

\section{HISTÓRICO DA GERAÇÃO DE ENERGIA COM ÊNFASE A PARTIR DA REVOLUÇÃO INDUSTRIAL NO MUNDO E NO BRASIL}

No início da existência humana, o homem primitivo dispunha apenas da energia dos alimentos que ingeria (GOLDEMBERG, 2008, p.58). Com a descoberta do fogo, passou a conservar e estocar comida, além de fabricar utensílios complexos (MURTA, 2011, p.09). A civilização em uma segunda etapa foi marcada milênios depois, pela união da água com o fogo, formando o vapor, que moveu inicialmente as máquinas da Revolução Industrial (HENRICHS, 2009, p.02). Consequentemente, com a mecanização, os métodos de produção se tornaram mais eficientes, ágeis e modernos. Logo, as mudanças trazidas pela industrialização demonstraram-se 
muito prósperas, pois pautadas na lógica da distribuição de riquezas, ideias de soberania de estado nacional, automatismo do progresso, classes, princípio do desempenho, natureza, realidade, conhecimento científico, etc. (BECK, 2010, p.10).

No setor energético, ${ }^{4}$ combustível do desenvolvimento, a dinamicidade de sua ampliação sempre foi uma exigência intrínseca. Assim, apesar da industrialização já em movimento, abastecida pela madeira, foram os combustíveis fósseis que possibilitaram o desenvolvimento prodigioso da humanidade (NGÔ, 2011, p.18). Todavia, a crise do petróleo (1973/1979) forçou a busca de alternativas energéticas, com investimento também na exploração offshore do petróleo (LEITE, 1997, p.224). A ocasião oportunizou ao gás substituir o petróleo em diversas aplicações (REIS, 2011, p. 136-139), bem como a energia atômica pela sua alta eficiência energética (MURTA, 2011, p.13). Surgiram ainda, como alternativa, as fontes renováveis, ${ }^{5}$ passando a tímida inclusão ao sistema que, em comparação com os combustíveis fósseis possui um custo de produção alto, impossibilidade de armazenamento e baixa densidade energética. ${ }^{6}$

Hoje, apesar da diversidade de fontes de geração de energia, a sociedade ainda é dependente dos combustíveis fósseis (NGÔ, 2011, p.07). O petróleo, o gás natural e o carvão, as principais fontes que predominam no mundo, todos combustíveis são fósseis,? (GIDDENS, 2010, p.57) logo, não renováveis (MURTA, 2011, p.16).

No Brasil, apesar da matriz energética ser composta em grande escala pela hidroeletricidade, o petróleo ocupa um papel relevante, e em menor proporção a termoeletricidade, a energia solar, dos ventos, nuclear, dentre outras fontes minoritárias de geração de energia (MURTA, 2011, p.22).

Percebe-se, neste breve realinhamento histórico, que diversas transições e modificações de paradigmas desencadearam a formação de uma sociedade contemporânea complexa, multifacetada, globalizada, de risco e pós-industrial (CARVALHOa, 2008, p.1). Muitas formas de estruturação, produção, sistematização da sociedade se transformaram de forma totalmente inconsequente, uma vez que as novas formas de geração de energia eram

\footnotetext{
${ }^{4}$ Quando fala-se em setor energético englobasse além da geração de eletricidade a produção de combustíveis seja eles renováveis ou não renováveis.

${ }^{5}$ Fontes de energia renováveis: são geradoras infinitas, pois possuem a capacidade de se renovar naturalmente. São inesgotáveis, por exemplo: energia solar, das águas, dos ventos, das biomassas, das marés, do calor e dos gases do interior da Terra. (MURTA, 2011.p.16.)

${ }^{6} \mathrm{Ou}$ seja, as fontes renováveis são um milhão de vezes menos concentradas que as fontes fósseis, como exemplo: são necessários 3.600 litros caindo de uma altura de 100 metros para produzir $1 \mathrm{kwh}$, enquanto bastam $70 \mathrm{~g}$ de gasolina para ter a mesma quantidade de energia. Além disso, os combustíveis fósseis são gratuitos, foram formados pela natureza em épocas em que a espécie humana não existia. Assim, o seu maior custo de produção está em descobrir jazidas e explorá-las, feito isso, o combustível estará gratuitamente disponível. (MURTA, 2011.p.16.)

${ }^{7}$ São substâncias de origem mineral formadas pelos compostos de carbono. Originam-se da decomposição de materiais orgânicos, mas como esse processo leva milhões de anos, são considerados recursos naturais não renováveis. Os mais conhecidos são o carvão mineral, o petróleo e seus derivados (como a gasolina e o óleo diesel) e ogás natural. São usados para movimentar motores de maquinas e veículos e para gerar energia, até mesmo elétrica (no caso das usinas termoelétricas). A queima desses combustíveis emite grandes quantidades de gases de efeito estufa, responsáveis pelo aquecimento global. (MURTA, 2011.p.11).
} 
testadas sem nenhum estudo acerca de suas consequências, sendo descoberto o seu insucesso somente após a ocorrência dos desastres ambientais.

\section{DEFINIÇÃO DE DESASTRES AMBIENTAIS}

Desastre ambiental é um evento sistêmico, ou seja, atinge toda (ou quase toda) uma comunidade, seus subsistemas e meio ambiente, com resultados de contingências diversas. (CARVALHO e DAMACENA, 2013, p.19-27). No ciclo de geração de energia, os desastres ambientais são, frequentemente, consequência da produção a partir de fontes não renováveis: vazamento de petróleo, explosão de gasoduto, explosão ou vazamento de material radioativo de usinas nucleares, explosão e emissão de gases na extração do carvão, dentre outros relacionados às particularidades do caso concreto. Desta maneira, os desastres ocorridos possuem um forte caráter agravante: são altamente complexos, não possuem clara previsibilidade, haja vista as incertezas científicas nas suas projeções (SLUIJS, 2006, p. 245-269).

De forma genérica, um evento classificado como um desastre possui consequências generalizadas, transtemporais, transterritoriais e muito graves que superam a capacidade dos governos locais e estaduais de prestarem o atendimento necessário diante de sua ocorrência (SUGARMAN, 2006). Isso se deve ao fato da natureza interligada da sociedade moderna que, mesmo os desastres em locais remotos podem ter sérias implicações em uma escala global (SMITH, 2005, p. 201-236).

No Brasil, o Decreto no 7.257, de 4 de agosto de 2010 dispõe sobre Sistema Nacional de Defesa Civil SINDEC, o reconhecimento de situação de emergência e estado de calamidade pública, transferências de recursos para ações de socorro, assistência às vítimas, restabelecimento de serviços essenciais e reconstrução nas áreas atingidas por desastre. Esta lei caracteriza os desastres como sendo o resultado de eventos adversos, naturais ou provocados pelo homem sobre um ecossistema vulnerável, causando danos humanos, materiais ou ambientais e consequentes prejuízos econômicos e sociais.

O Centre of Research on The Epidemiology of Disasters - CRED define um desastre como uma situação que supera a capacidade local necessitando solicitar ajuda externa, sendo um imprevisto e, muitas vezes, um súbito evento que causa grande dano, destruição e sofrimento humano. Assim, para que o evento seja classificado como um desastre, pelo International Disaster Database - EM-DAT, ao menos um dos critérios que seguem devem ser preenchidos: i) 10 (dez) ou mais mortes; ii) pelo menos 100 pessoas afetadas (necessitando de comida, água, cuidados básicos e sanitários; desalojados e feridos); iii) ter sido declarado estado de emergência; iv) ter havido um pedido de ajuda internacional (CRED,2012). Não estando presentes nenhum deste itens, o evento não é classificado como desastre ambiental.

Em Smith (2005, p. 201-236) as redes de conexões que podem moldar a dinâmica da ocorrência e 
definição de uma catástrofe envolvem todo o sistema da sociedade, sendo sua origem voltada para lugar, ${ }^{8}$ espaço ${ }^{9}$ e tempo ${ }^{10}$ do desencadeamento de todo o processo.

Urry (2005, p. 201-236) argumenta que existem 05 (cinco) elementos-chave no interior dos processos de globalização, que podem ser vistos como tendo uma relevância para esta definição. Estes elementos são vistos como estrutura, fluxo, ideologia, desempenho e complexidade e eles podem ser utilizados como uma estrutura através da qual ilustra a natureza "multinível" dos desastres. Este mosaico de elementos serve para gerar uma dinâmica emergente do conjunto de questões que qualquer comunidade ou rede exposta vai enfrentar às pertubações e danos associados a um desastre.

Ora, não obstante as evidentes dificuldades de configuração de um conceito unânime e determinado para desastres ambientais, a partir das suas consequências tem-se que a acepção técnica do termo, aqui utilizado em seu sentido jurídico, não se refere a um plano individual (perda de propriedade, comprometimento de saúde, individualmente consideradas), mas diz respeito a eventos que atuam no plano da sociedade, geralmente entendidos como eventos de grandes perdas para um número substancial de pessoas, bens e meio ambiente (SUGARMAN, 2006).

Por estes motivos, os desastres estão diretamente ligados à ideia de eventos capazes de desestabilizar um sistema ao ponto de que este perca a capacidade de diferenciação funcional, operacionalização e assimilação do evento rapidamente. Tal colapso gera, por evidente, uma incapacidade de assimilação e recuperação rápida, sendo, por esta razão, a resiliência um conceito central na descrição das catástrofes. Em tal perspectiva, os desastres envolvem sempre a ocorrência inesperada ou repentina que demanda uma ação imediata. Mesmo que um desastre não possa ser caracterizado como inesperado, em muitos casos, este demandará uma ação de socorro imediata, sob pena, de potencialização de sua magnitude. Trata-se de um fenômeno que envolve, na condição de atingido, comunidades, não devendo ser pensado, para sua configuração (como desastre) como um fenômeno de lesões individuais (CARVALHO e DAMACENA, 2013, p.31), mas sim, como dito, um evento que atinge todo o sistema (sociedade + meio).

Diante da análise da legislação brasileira acerca da atuação nos desastres (Lei 7.257/2010) percebe-se que diferentemente de outros sistemas e organizações, esta legislação inclui além dos danos aos bens e ao homem, também os prejuízos que atingem o ecossistema vulnerável, o que se demonstra de suma importância para a análise dos desastres ambientais.

Importa ressaltar que ecossistemas saudáveis proporcionam uma variedade de serviços essenciais, uma

\footnotetext{
${ }^{8}$ Diz respeito a local que originou o evento e que atingiu a sociedade local.

${ }^{9}$ Espacialmente, o impacto das ameaças é extremadamente variado. Portanto, alguns desastres são isolados e localizados; outros são difusos e dispersos.

${ }^{10}$ Está relacionado as consequências que ao longo do tempo e do espaço um desastre pode causar.
} 
vez que são responsáveis pela interação dos seres vivos com o meio ambiente, proporcionando as condições e os processos que sustentam a vida humana. Como por exemplo: a purificação de ar e água, desintoxicação e decomposição de resíduos, renovação da fertilidade do solo, regularidade climáticas, secas e inundações de mitigação, o controle pragas e plantas polinizadoras, dentre outros (SALZMAN, 2001, p.310-312).

Em suma, mais do que nunca desastres naturais, tecnológicos e sociais são cada vez mais internacionalizados, estão interligados com o curso dos assuntos humanos de maneira que eram inimagináveis décadas atrás. O movimento global rápido do capital e padronização de informações, a importância de um desastre com as políticas geoestratégicas, e o crescimento multinacional de pobreza e marginalização teve uma influência sobre a nossa interpretação de calamidade na modernidade do mundo. Por isso, desastres são racionalizados ou interpretados de acordo com os cânones e preocupações do período contemporâneo moderno, interpretações são cada vez mais dominadas pelas novas formas de simbolismo construído pela indústria de comunicação de massa (ALEXANDER, 2005, p.25-39).

\section{DESASTRES DE RELEVÂNCIA MUNDIAL}

A SOS Mata Atlântica enumera os 10 maiores acidentes petrolíferos da história do mundo, os quais juntos respondem por $68 \%$ dos vazamentos de petróleo mais graves já registrados nos últimos 70 anos. Neste levantamento, o primeiro lugar é ocupado pelo desastre da Guerra do Golfo com 1.360.000 (um milhão, trezentos e sessenta mil toneladas) de petróleo despejados.

\section{Tabela 1 - Lista dos piores desastres com petróleo no mundo.}

\begin{tabular}{|c|l|c|l|l|}
\hline Posição & \multicolumn{1}{|c|}{ Nome } & Ano & \multicolumn{1}{c|}{ Localização } & Volume \\
\hline 1 & Guerra do Golfo & 1991 & Kuwait, Golfo Pérsico & 1.360 .000 toneladas \\
\hline 2 & Deepwater Horizon & 2010 & Golfo do México & 5 milhões de barris \\
\hline 3 & Ixtoc I & 1979 & Campeche, Golfo do México & 454.000 toneladas \\
\hline 4 & Fergana Valley & 1992 & Uzbequistão & 285.000 toneladas \\
\hline 5 & Atlantic Empress & 1979 & Tobago, Caribe & 287.000 toneladas \\
\hline 6 & Nowruz & 1983 & Angola & 260.000 toneladas \\
\hline 7 & ABT Summer & 1991 & Angola & 260.000 toneladas \\
\hline 8 & Castillo de Bellver & 1983 & Africa do Sul & 252.000 toneladas \\
\hline 9 & Amoco Cadiz & 1978 & França & 223.000 toneladas \\
\hline 10 & M T Haven & 1991 & Itália & 144.000 toneladas \\
\hline
\end{tabular}

Fonte: Tabela adaptada da fonte SOS Mata Atlântica.

Especificamente no Brasil, a ocorrência de desastres envolvendo o petróleo é imensa, mas em sua maioria, em comparação com os piores desastres mundiais, são tidos como de pequena magnitude, os principais são: 
Tabela 2 - Lista dos piores derramamentos de petróleo no Brasil.

\begin{tabular}{|c|c|c|c|c|}
\hline Data & Fonte & Local & $\begin{array}{c}\text { Quantidade } \\
\text { Derramada }\left(\mathrm{m}^{3}\right)\end{array}$ & Produto \\
\hline 06/12/1960 & Sinclair Petrolore & Costa brasileira & 66.600 & Petróleo \\
\hline 8/1974 & Takimyia Maru & Canal de São Sebastião, SP & 7.000 & Petróleo \\
\hline 29/08/1974 & Esso Garden State & Porto ou terminal indefinido & 5.882 & Petróleo \\
\hline 26/03/1975 & Tarik Ibn Ziyad & Baía de Guanabara, RJ & $7.000-18.000$ & Petróleo \\
\hline 09/01/1978 & Brazilian Marina & Canal de São Sebastião/ SP & $6.000-41.525$ & Petróleo \\
\hline 26/05/1978 & Aminona & Banco do Meio, ZEE & 23.305 & Óleo combustivel 2 \\
\hline 27/10/1979 & Gunvor MAERSK & Rio Amazonas & $12.780-17.479$ & Óleo combustivel ou derivado claro. \\
\hline $14 / 10 / 1983$ & Oleoduto & São Sebastião - Cubatão (SP) & 2.500 & Petróleo \\
\hline $17 / 03 / 1985$ & Marina & São Sebastião/ SP & $2.000-2.782$ & Petróleo \\
\hline $12 / 1986$ & Brotas & Litoral RJ & 1.600 & Petróleo \\
\hline 15/05/1994 & Oleoduto & São Sebastião - Cubatão (SP) & 2.700 & Petróleo \\
\hline 10/02/1997 & Oleoduto & Baía de Guanabara, RJ & $900-3.000$ & Óleo combustivel marítimo \\
\hline $18 / 01 / 2000$ & Oleoduto & Baía de Guanabara, RJ & 1.292 & Óleo combustivel marítimo \\
\hline $16 / 07 / 2000$ & Oleoduto & Rio Barigũi, PR & 4.000 & Petróleo \\
\hline $18 / 02 / 2004$ & Oleoduto & São Sebastião - Cubatão (SP) & $?$ & Petróleo \\
\hline $15 / 11 / 2004$ & Vicuña & Paranaguá, PR & 6.555 & $\begin{array}{l}\text { Óleo combustivel marítimo, óleo } \\
\text { diesel, óleo hidráulico e metanol. }\end{array}$ \\
\hline
\end{tabular}

Fonte: Souza Filho (SOUZA FILHO, 2006, p. 137).

O Greenpeace declarou que o acidente da Chevron se assemelha ao do Golfo do México. A empresa Transocean que perfurou os poços e que ocasionou o vazamento, é a mesma que operava com a BP no episódio norte-americano (GREENPEACE,2011). A Agência Nacional de Petróleo Gás Natural e Biocombustíveis-ANP revelou que foram detectadas falhas gravíssimas em equipamentos na plataforma de propriedade da Transocean, demonstrando a precariedade das condições em que a Chevron promovia a perfuração dos poços de petróleo. Embora constasse em seu Plano de Emergência Individual - PEI, a Chevron não tentou recolher o óleo do mar, optando pelo uso da dispersão mecânica, que causou o espalhamento do petróleo e agravou o desastre ambiental (REUTERS BRASIL, 2011).

Diferentemente dos acidentes petroliferos, os acidentes nucleares são poucos, mas causaram e ainda causam danos incalculáveis perceptíveis pelo homem e pela natureza. De acordo com a escala INES (International Nuclear Event Scale) os que mais se destacaram foram: 
Tabela 3- Lista dos piores desastres nucleares no mundo.

\begin{tabular}{|c|l|c|}
\hline INES & \multicolumn{1}{|c|}{ Localização } & Data \\
\hline 7 & Chernobyl, Ucrânia & $\mathbf{1 9 8 6}$ \\
\hline 7 & Fukushima, Japão & $\mathbf{2 0 1 1}$ \\
\hline 6 & Kyshtym, Rússia & 1957 \\
\hline 5 & Windscale Fogo (Sellafield), Reino Unido & 1957 \\
\hline 5 & Three Mile Island, Pensilvânia Eua & 1979 \\
\hline 4 & Tokaimura, Japão & 1999 \\
\hline 4 & Saint-Laurent, França & 1980 \\
\hline 4 & 1Sl-Usina Experimental, IdahoEua & 1961 \\
\hline 4 & Buenos Aires, Argentina & 1983 \\
\hline 3 & Sellafield, Reino Unido & 2005 \\
\hline 3 & Vandellos, Espanha & 1989 \\
\hline 2 & Atucha, Argentina & 2005 \\
\hline 2 & Cadarache, França & 1993 \\
\hline 2 & Forsmark, na Suécia & 2006 \\
\hline 1 & $\begin{array}{l}\text { Violação dos limites de operação em uma } \\
\text { instalação nuclear. }\end{array}$ \\
\hline
\end{tabular}

Tabela compilada a partir dos dados da fonte: The international nuclear and radiological event scale.

Como visto, os desastres ambientais decorrentes de acidentes nucleares são avaliados em níveis de acordo com a tabela The International Nuclear And Radiological Event Scale- INES (Escala Internacional de Eventos Nucleares e Radiológicos).

De outro lado, os desastres decorrentes da exploração do carvão são menos frequentes que no petróleo, mas resultam em diversas vítimas, conforme acidentes que seguem:

\begin{tabular}{|c|c|c|}
\hline Ano & Nome & Local \\
\hline 1866 & Oaks $^{l 1}$ & Reino Unido \\
\hline 1906 & Courrières $^{l 2}$ & França \\
\hline 1907 & Monongah $^{13}$ & Estados Unidos \\
\hline 1913 & Senghenydd $^{l 4}$ & Reino Unido \\
\hline
\end{tabular}

\footnotetext{
${ }^{11}$ Oaks é o segundo desastre mais mortiffero da mina de carvão no Reino Unido após o desastre na mina de carvão Senghenydd. $O$ número de mortos deste grande desastre da mina de carvão é de 388. Foi uma explosão de gases e pó de carvão. Suspeita-se que tenha sido provocada pela escavação de novos trabalhos na mina subterrânea. (MINING - TECNOLOGY, 2014)

${ }^{12} \mathrm{O}$ desastre teve um número total de mortos de 1.099, é o segundo desastre de mineração de carvão mais mortal da história. Uma fagulha de fogo subterrâneo desencadeou uma maciça explosão que destruiu virtualmente um vasto labirinto de minas (OPERA MUNDI, 2011).

${ }^{13}$ É a maior catástrofe mineira nos Estados Unidos. O desastre foi causado pelo grisu e explosão de pó de carvão e matou 362 pessoas (MINING - TECNOLOGY, 2014).

14 Este é a pior tragédia mineira no Reino Unido. Também é conhecido como a Explosão Senghenydd, foi o resultado de uma explosão de pó de carvão em mina subterrânea com a morte de 439 mineiros. A maioria dos mineiros que sobreviveram ao incêndio e explosão foram mortos devido a intoxicação por monóxido de carbono (MINING - TECNOLOGY, 2014).
} 


\begin{tabular}{|c|c|c|}
\hline 1914 & $\begin{array}{c}\text { Mitsubishi } \\
\text { Hojyo }^{I 5}\end{array}$ & Japão \\
\hline 1942 & $\underset{16}{\text { BenxihuColliery }}$ & China \\
\hline 1960 & Laobaidong $^{17}$ & China \\
\hline 1960 & Coalbrook $^{18}$ & África do Sul \\
\hline 1963 & Mitsui Miike $e^{19}$ & Japão \\
\hline 1965 & Dhanbafo & Índia \\
\hline 1972 & $\underset{21}{\text { WankieColliery }}$ & $\begin{array}{l}\text { Rodésia (hoje } \\
\text { Zimbabwe) }\end{array}$ \\
\hline 2008 & Kingston $^{22}$ & Estados Unidos \\
\hline 2014 & Soma $a^{23}$ & Turquia \\
\hline
\end{tabular}

Tabela compilada a partir dos dados das fontes referidas.

$\mathrm{Na}$ geração de energia a partir do gás, os desastres são aparentemente pouco frequentes, mas em sua ocorrência as consequências são verdadeiramente catastróficas e por este motivo exigem maior cautela. Dentre os desastres, os mais destacados são:

\footnotetext{
${ }^{15}$ Foi o pior acidente de mineração no Japão. Ele causou 687 mortes e foi originado por uma explosão de gás na mina de carvão (EPIC DISASTERS, 2015).

${ }^{16} \mathrm{O}$ desastre custou 1.549 vidas e é considerado como o pior desastre de mineração de carvão (MINING - TECNOLOGY, 2014).

${ }^{17}$ Este foi o segundo mais letal na China após o desastre mina Benxihu, matou 684 pessoas (MINING - TECNOLOGY, 2014).

${ }^{18} \mathrm{O}$ colapso subterrâneo foi causado pela desintegração de cerca de 900 pilares subterrâneos que suportam os telhados túnel. Cerca de 1.000 mineiros estavam no subsolo trabalhando no momento do colapso (EPIC DISASTERS, 2015).

${ }^{19}$ Este foi o segundo desastre mais mortífero de mineração de carvão no Japão. Neste desastre, 458 mineiros morreram e 833 ficaram feridos (COAL INVESTING NEWS, 2014).

${ }^{20} \mathrm{O}$ desastre foi causado por uma explosão em que 375 mineiros morreram. O acidente foi em razão da explosão de grisu e pó de carvão. A ignição inicial é suspeita de ter vindo da lanterna de furacão de uma pessoa que entrou na galeria subterrânea. $\mathrm{A}$ administração da mina alegou que foi um ato intencional(COAL INVESTING NEWS, 2014).

${ }^{21}$ Este desastre matou 426 pessoas e foi causado por várias explosões na mina subterrânea de carvão(COAL INVESTING NEWS, 2014).

${ }^{22}$ Um muro de contenção em cinzas lagoa da Fossil da Usina Kingston quebrou, derramando 5,6 milhões de metros cúbicos de cinzas de carvão molhado. Estudos sugerem que este tipo de cinzas de carvão pode conter altos níveis de metais pesados e substâncias cancerígenas (IO9 WE COME FROM THE FUTURE,2010).

${ }^{23} \mathrm{~A}$ mina de carvão onde trabalhavam 787 pessoas explodiu (NEW YORK TIMES, 2014).
} 


\begin{tabular}{|c|c|c|}
\hline Ano & Nome & Local \\
\hline 1937 & New London Schoof4 & Estados Unidos \\
\hline 1944 & Cleveland East $^{25}$ & Estados Unidos \\
\hline 1978 & Train WreckemWaverly $^{26}$ & Estados Unidos \\
\hline 1984 & San Juanico $^{27}$ & México \\
\hline 1989 & Ufa Train $^{28}$ & Russia \\
\hline 1994 & Edison $^{29}$ & Estados Unidos \\
\hline 2004 & Skikda $^{30}$ & Argélia \\
\hline
\end{tabular}

Tabela compilada a partir dos dados das fontes referidas para cada evento.

Por outro lado, a energia hidrelétrica, fonte de alterações ecológicas e hidrológicas, de erosão, propagação de certas doenças tropicais nos países quentes, tem em sua história diversos acidentes.

O colapso de barragens em todo o mundo é o mais frequente e que causou vítimas mais imediatas do que qualquer outra fonte de geração de energia. As estatísticas mostram que a frequência de falhas em barragens dependente da localização geográfica, do tipo e da idade de uma represa. Todavia, os dados sobre os danos atribuíveis a acidentes em hidrelétricas são muito controversos. Muitas barragens são usadas para controle de enchentes, proporcionando o acesso à terra agrícola que de outra forma teria sido regularmente inundada, e que reservatórios frequentemente satisfazem as necessidades polivalentes (THE INTERNATIONAL ENERGY AGENCY, 2002).

Relação dos acidentes mais graves e conhecidos ocorridos em barragens de hidrelétricas:

\footnotetext{
${ }^{24}$ A explosão destruiu a High School da cidade de New London e matou cerca de 298 dos 500 alunos do edifício (AMERICAN OIL \& GAS HISTORICAL SOCIETY).

${ }^{25}$ Um tanque de armazenamento preenchido com mais de 90 milhões de metros cúbicos de gás natural explodiu, destruindo tudo que se encontrada dentro de um raio de uma milha, ocasionando 200 mortes. (COUNTERSPILL, 2011).

${ }^{26}$ Um carro tanque, carregado com 2.000 galões de propano, descarrilhou e explodiu. Dados apontaram que 11 pessoas foram mortas e 145 feridos, além de ocasionar um dano mensurado em 1,8 milhões de dólares. (GENDISASTERS, 2013).

${ }^{27}$ Devido a uma série considerável de explosões em um Gás Liquefeito de Petróleo (GLP) de tancagem. As explosões matando 500 a 600 pessoas e ferindo 5.000 à 7.000 devido a queimaduras graves (UNIVERSAL ROVER, 2013).

${ }^{28}$ Dois trens de passageiros que se passam entre as cidades de Ufa e Asha acendeu uma explosão proveniente da mistura de hidrocarbonetos ao ar a partir de um vazamento de gás liquefeito de petróleo. $\mathrm{O}$ acidente, além de ferir centenas de pessoas com queimaduras graves, resultou em mais de 500 mortes (ATROPEDIA).

${ }^{29}$ A explosão de gás natural em uma tubulação de gás natural subterrâneo destruiu oito edifícios de apartamentos em um incêndio feroz. Vinte e nove moradores foram feridos e centenas obrigados a fugir (GENDISASTERS, 2013).

${ }^{30} \mathrm{Ha} 500$ quilômetros a leste de Argel, ocorreu a explosão de uma fábrica de liquefação de gás natural em Skikda. Pelo menos 27 pessoas morreram e 74 ficaram feridas (OUTER SPACE, 2014).
} 


\begin{tabular}{|c|c|c|}
\hline Ano & Nome & Local \\
\hline 1975 & Henan $^{31}$ & China \\
\hline 1963 & VajontDam $^{32}$ & Itália \\
\hline 2009 & Sayano-Shushenskaya $^{33}$ & Rússia \\
\hline 2000 & Bieudron $^{34}$ & Suíça \\
\hline 1956 & Power StationSchoellkopf $^{35}$ & Estados Unidos \\
\hline 1979 & Machhus $^{36}$ & Índia \\
\hline 2008 & Koshi $^{37}$ & Nepal \\
\hline 1976 & TetonDam $^{38}$ & Estados Unidos \\
\hline 2012 & Santo Antônio $^{39}$ & Brasil \\
\hline
\end{tabular}

Tabela compilada a partir dos dados das fontes referidas para cada evento.

Em suma, a partir dos dados expostos, pode-se afirmar que todos são desastres e, mesmo que de diferentes tipos e proporções, geraram inúmeros danos. Como consequência, verifica-se que somente mediante uma análise do funcionamento da sociedade como um todo será possível instrumentalizar mecanismos a se evitar ou atenuar os danos dos desastres. A sistematização depende da sociedade (meio ambiente, Direito, política, economia, dentre outros) e, partindo-se desta premissa, a teoria sistêmica de Luhmann serve como mecanismo

\footnotetext{
${ }^{31}$ As causas desta catástrofe foram técnicas. Estima-se que a inundação matou de imediato 85.000 pessoas e que 145.000 morreram após devido as epidemias e a fome que atingiu a região após o dilúvio. Ele também causou a perda repentina de $18 \mathrm{GW}$ de energia, o equivalente à produção de cerca de nove grandes modernas a carvão poder centrais térmicas (THE INTERNATIONAL ENERGY AGENCY,2002).

${ }^{32}$ Durante o enchimento do reservatório um bloco de cerca de 260 milhões de $\mathrm{m}^{3}$ se destacou e deslizou para dentro do lago com velocidades de até $30 \mathrm{~m} / \mathrm{seg}$ (aprox. $110 \mathrm{~km} / \mathrm{h}$ ). Isto gerou uma onda que liderou a barragem de $245 \mathrm{~m}$ e varreu para o Vale do Longarone abaixo, com a perda de cerca de 2.000 vidas. Os sinais de aviso e avaliações negativas durante as fases iniciais do projeto foram desconsiderados (ENVIRONMENT AND SOCIETY, 2011).

${ }^{33} \mathrm{~A}$ hidrelétrica sofreu uma catastrófica "onda de pressão" conhecida como martelo hidráulico. O golpe repentino da água provocou ejeção da turbina e arrancou todos os equipamentos auxiliares das bases que juntos totalizavam uma massa de 900 toneladas. A água imediatamente inundou a sala das máquinas e das turbinas causando curto-circuito e explosão de um transformador e consequentes danos elétricos nas demais turbinas. Além das 76 mortes, os danos computados foram de US $\$ 310$ milhões (CRUZ,2009).

${ }^{34} \mathrm{~A}$ usina hidrelétrica rompeu-se. $\mathrm{O}$ vazamento de mais de $70.000 \mathrm{~m}^{3}$ d'água não só causou danos drásticos à região, como também, infelizmente, causou a morte de três pessoas. Este acidente foi amplamente investigado por diversos peritos internacionais (HYDRONEWS, 2010).

${ }^{35}$ Seis geradores capazes de produzir 322.500 cavalos de potência foram demolidos. Um trabalhador morreu. Os danos foram estimados em 100 milhões de dólares. $\mathrm{O}$ mais devastador foi a súbita perda de 400 mil quilowatts de energia da rede elétrica (NIAGARA FALLS INFO).

${ }^{36} \mathrm{~A}$ barragem desabou levando a um dilúvio na cidade industrial de Morbi, destruindo milhares de casas e vidas. A contagem final a morte foi estimada entre 5.000 e 10.000 (INDIA WATERPORTAL, 2012).

${ }^{37}$ Quando os sedimentos depositados nas áreas inundadas originaram uma erosão e rompimento que ocasionou além da alteração do curso do rio, a perda de 527 vidas, 116 milhares de hectares de terra inundados, 234 mil pessoas desabrigadas e sobre 1500 $\mathrm{Km}^{2}$ de terra ficaram inúteis pois cobertos por uma espessa camada de areia estéril e seca. (DEVKOTA, 2012).

${ }^{38}$ Situada 44 quilômetros a nordeste de Idaho Falls, Estados Unidos, a Teton Dam durante o enchimento inicial do reservatório, rompeu-se e lançou cerca de 300.000 acre feet de água, nos campos agrícolas, em seguida, inundou as cidades a jusante e ocasionou a perda de 14 vidas e seu custo foi estimado em quase 1 bilhão de dólares (SYLVESTER).

${ }^{39} \mathrm{O}$ rompimento na barragem da Usina Hidrelétrica de Santo Antônio, no município de Laranjal do Jari, Amapá, resultou em 04 mortes, 4 mil pessoas precisam ser retiradas de suas casas, 1 mil famílias foram afetadas, 590 pessoas desabrigadas. Segundo a prefeitura, o evento gerou o desalojamento de $20 \%$ da população, mais de trezentas quedas de barreiras e quase 100 casas foram destruídas nos deslizamentos (AMAZÔNIA).
} 
norteador destas atuações, haja vista que os desastres são o resultado de uma falha sistêmica da sociedade, onde também mora o seu remédio.

\section{TEORIA SISTÊMICA E DESASTRES AMBIENTAIS}

Diante da compreensão dos desastres ambientais como um fenômeno sistêmico, dada a sua magnitude e complexidade acerca dos seus danos e envolvidos. A teoria sistêmica de Luhmann demonstra-se eficaz para a elaboração deste estudo acerca da definição das respostas que o Direito precisa introduzir no gerenciamento da distribuição dos riscos e consequentemente dos desastres ambientais no ciclo de geração de energia.

Como embasamento teórico, a partir da visão sistêmica de Luhmann, a sociedade se apresenta com características de um sistema, permitindo a compreensão dos fenômenos sociais através dos laços de interdependência que os unem e os constituem numa totalidade (ROCHA, 2007, p.51). Subsequentemente, a sociedade é formada por diversos sistemas diferenciados funcionalmente (LUHMANN, 2007, p. 69-70), em que o processo de diferenciação do sistema para com o outro sistema decorre das interferências ("irritações") provocadas pelo seu meio (ambiente) (LUHMANN, 2007, p. 69-70).

Por isso, as irritações são resultado do próprio estímulo do sistema, das observações realizadas. Luhmann denomina como contingência as possibilidades de escolha do sistema, a qual esta intimamente ligada ao risco, uma vez que oportuniza uma variedade de alternativas de atuação com um grau de liberdade. Além disso, o sistema afora ter de conviver com suas próprias contingências precisa enfrentar o resultado das contingências dos subsistemas (dupla contingência) (LUHMANN, 2007, p. 30).

Nesta ocasião que surge o risco, a liberdade de escolha diante das observações dos subsistemas para o sistema se coloca como verdadeira insegurança, (LUHMANN, 2007, p. 30) já que, cada subsistema de acordo com seu histórico e especialidade observará e compreenderá determinado fato de forma particular e, consequentemente, distinta.

Logo, o processo de modernização, típico da sociedade industrial, tornou o sistema social ainda mais complexo e multifacetado, não sendo este mais capaz de controlar a ele próprio. O processo, então, é aplicado a si mesmo, já que a sociedade vive sob o domínio absoluto da modernização da indústria. Esta modernização, em virtude de sua autonomização, subtrai de si mesma os próprios fundamentos (DE GIORGI, 1994, p. 45-54).

Nasce de tal modo, uma segunda modernidade que é a sociedade de risco. Esta sociedade começa onde falham os sistemas de normas sociais que prometiam segurança, pela incapacidade de controlar as ameaças que provêm das decisões frente aos novos desafios. As ameaças são diversas, de natureza ecológica, tecnológica, política, dentre outras, e as decisões são resultado de coações que derivam da racionalidade econômica que impõe o modelo de racionalidade universal (DE GIORGI, 1994, p. 45-54). 
Destarte, a sociedade se vê desafiada por riscos que antes eram desconhecidos, mas que podem ensejar, até mesmo, a autodestruição de toda a vida do planeta terra. E que sua prevenção e precaução está condicionada a tomada de decisões pautadas no binômio probabilidades/magnitude. Mas, que não trazem certezas, mas sim hipóteses dos possíveis danos irreversíveis e incalculáveis (desastres ambientais). Outrossim, sob as condições de possibilidade da racionalidade e principalmente da convicção, o futuro depende das decisões (LUHMANN, 1992, p. 36). Renunciar os riscos significa - sobretudo nas condições atuais - renunciar a racionalidade (LUHMANN, 1992, p. 59).

Neste contexto, a concepção de "sociedade de risco" torna ultrapassada toda a sociologia clássica voltada para a segurança social. O risco exige uma nova racionalidade para a tomada das decisões nas sociedades, redefinindo a filosofia analítica, a uma teoria da sociedade mais realista (ROCHA, 2007, p.52). A consciência do risco é uma das condições para a constituição de uma gestão dos riscos à prevenção e precaução dos desastres ambientais.

O risco, destarte, é a modalidade secularizada de construção do futuro. Já que a perspectiva de risco torna plausíveis pontos de vista diferentes da racionalidade, na condição de que estes sejam capazes de rever os próprios pressupostos operativos e na condição de que haja tempo para efetuar esta revisão (DE GIORGI, 1994, p. 45-54).

Para tanto, o Direito, ainda muito pautado em eventos passados, precisa se reestruturar e passar a vincular o futuro, ou seja, decisões que impeçam/mitiguem a ocorrência do desastre e não somente vislumbrem a obrigação de reparação após a sua ocorrência. Assim, o Direito ainda possui dificuldades em sistematizar sua atuação voltada para o controle do futuro, como explana Carvalho (2008, p.24):

O Direito apresenta-se como um sistema comunicacional fundado em programações condicionadas altamente vinculadas e vinculadoras das decisões presentes no passado (deve-se lembrar que leis, doutrina e jurisprudência consistem em condensações de experienciais passadas), ao passo que as questões que dizem respeito à tutela ambiental exigem que sejam levadas em consideração as consequências futuras (riscos) das ações e das tomas de decisão no Direito e na sociedade."

No mesmo sentido, Luhmann (2005, p. 188-189):

$[\ldots]$ el derecho tiene que ver con los costos sociales que se desprenden de los enlazamientos del tiempo que efectúan las expectativas. En concreto, se trata de la función de estabilización de las expectativas normativas a través de la regulación de la generalización temporal, objectual y social. El derecho permite saber qué expectativas tienen un respaldo social (y cuáles no). Existiendo esta seguridad que confieren las expectativas, uno se puede enfrentar a los desencantos de la vida cotidiana; o por lo menos se puede estar seguro de no verse desacreditado en relación a sus expectativas.

O Direito, para Luhmann, embora visto como uma estrutura, é dinâmico devido à permanente evolução provocada pela sua necessidade de constantemente agir como uma das estruturas sociais redutoras da complexidade das possibilidades do ser no mundo. Nesta ordem de raciocínio, a pesquisa jurídica deve ser dirigida para uma nova concepção da sociedade centrada na complexidade, baseada em postulados como os riscos e os 
paradoxos. Um sistema diferenciado deve, simultaneamente, ser operativamente fechado para manter a sua unidade e cognitivamente aberto para poder observar a sua diferença constitutiva (ROCHA, 2007, p.51-52).

Sob este pressuposto, é aplicável a Teoria do Risco Abstrato, que tem o intuito de sistematizar/gerenciar os riscos de danos ambientais com instrumentos do Direito Ambiental, a fim de garantir a qualidade de vida das atuais e futuras gerações (CARVALHO, 2008, p.133-138). Esta teoria impõe a obrigação de considerar os danos futuros, em que importam sejam considerados nos processos de decisão os interesses/direitos das futuras gerações (CARVALHO, 2008, p.133-138).

De tal modo, a gestão dos riscos e perigos catastróficos depende, por evidente, de um regime jurídico capaz de, em um primeiro momento promover a identificação técnica e em seguida realizar a antecipação jurídica às catástrofes (CARVALHO, 2012, p.107-146). ${ }^{40}$ Evidenciada a problemática da constatação dos riscos ambientais da atividade, será possível quantificar estes riscos. E, diante da constatação do risco, será possível identificar os riscos e, mediante este conhecimento, tomar as medidas jurídicas/judiciais necessárias a se evitar os desastres ambientais.

Logo, é precisa-se de instrumentos capazes de promover a gestão dos riscos gerados pela produção de energia, pois sem ela não haverá desenvolvimento, economia e evolução. Tem-se sim, como conjugar o crescimento com a preservação ambiental, é possível desenvolver sustentável. Mas, para tanto, não podem ser medidos esforços pela sociedade como um todo.

Desastres ambientais no ciclo de geração de energia são consequência de falhas na gestão dos riscos, resultando na destruição, mortes, doenças, no comprometimento de infraestruturas e danos irreversíveis. São o resultado da geração de energia sem considerar os riscos implicados. Para tanto, a matriz teórica do Direito voltado para atuação em eventos futuros necessita estar baseada na Teoria Sistêmica e condicionada a probabilidade e a magnitude do risco vir a ser o estopim de um Desastre Ambiental.

\section{CONSIDERAÇÕES FINAIS}

Diante dos acontecimentos supracitados, percebe-se que nos eventos catastróficos ocorridos no ciclo de geração de energia é de suma importância que sua magnitude e classificação como desastre se dê não apenas pelo número de humanos atingidos, mas sim pelos danos ecossistêmicos causados que, na maioria ou totalidade, são supervenientes.

Logo, acidentes no setor de energia, na maioria dos casos afetam a saúde e os bens da sociedade atingida, degradam os ecossistemas e suas funções. Assim, a proteção de infra-estruturas críticas no setor de energia é imprecindível, pois a oferta de energia suficiente e contínua constitui a espinha dorsal da atual sociedade. 
Os acidentes no setor de energia são ou deveriam ser uma séria preocupação das autoridades diante dos cenários catastróficos que podem causar, por isso, a consideração dos fluxos de energia é essencial. Porquanto, um acidente pode acontecer em qualquer fase da cadeia: exploração, extração, processamento, armazenamento, transporte de longa distância, distribuição regional e local, geração, tratamento de resíduos e disposição final.

Ora, em vez de reprimir os riscos, é essencial a elaboração de um sistema de gestão, de monitoramente dos riscos ambientais, antropogênicos e híbridos, a fim de enfrentar o potencial catastrófico dos sistemas. A síndrome da cegueira do desastre não possui uma cura fácil e, talvez, nunca terá. Os desastres estão além da imaginação humana e para que haja um controle dos riscos para sua ocorrência é necessária uma conjugação de toda a sociedade sistêmica envolvida, em todas as fases dos empreendimentos para uma efetiva gestão de riscos.

Para tanto, o Direito, ainda muito pautado em eventos passados, precisa se reestruturar e passar a vincular o futuro, ou seja, decisões que impeçam/mitiguem a ocorrência do desastre e não somente vislumbrem a obrigação de reparação após a sua ocorrência. Assim, o Direito ainda possui dificuldades em sistematizar sua atuação voltada para o controle do futuro. Logo, sua matriz teórica jurídica deve estar fundamentada na Teória Sistêmica e no condicionamento da atuação futura baseada na probalidade e magnitude do risco de ocorrência de desastres ambientais.

\title{
THE LEGAL THEORETICAL MATRIX OF ENVIRONMENTAL DISASTERS IN ENERGY GENERATION CYCLE IN SYSTEMIC SOCIETY
}

\begin{abstract}
Since the Industrial Revolution, production mechanisms have become more dynamic, automatic, and, following these scientific progress increased new models of exploratory development, including power generation mechanisms. However, despite numerous advantages of these new development format, it results in a distribution of systemic risks, which do not distinguish time limits, generational or territorial and cause environmental disasters, with very worrying consequences. These disasters which generate damage to the environment, the community, the economy, among other affected subsystems are unknown and are not absorbed by the Law causing uncontrolled legal operations to contain the disaster risks. Thus, from the analysis important catastrophic events in the world, this article makes use of literature as a methodology in order to achieve your goal is to understand the environmental disaster in the power generation cycle, its relationship with systemic society and imposing the readaptation Law oriented to future events on the basis of systemic Theory.
\end{abstract}

Keywords: disasters; energy generation; risk.

${ }^{40}$ No presente trabalho entende-se catástrofe como sinônimo de desastre. 


\section{REFERENCIAS}

ALEXANDER, David. An interpretation of disaster in terms of changes in culture, society and international relations. In: PERRY, Ronald W. Perry; QUARANTELLI, E.L. What is a disaster? new answers to old questions.EstadosUnidos da América: Xlibris Corporation, 2005. p.25-39. Disponível em: <http://www.saarcsadkn.org/downloads/what\%20is\%20disaster.pdf>. Acesso em: 15 mai. 2016.

AMAZÔNIA. Amapá: 4 pessoas desaparecem em rompimento de barragem,2014.Disponível em:<http://amazonia.org.br/2014/03/amap\%C3\%A1-4-pessoas-desaparecem-em-rompimento-debarragem/>. Acesso em: 21 mai. 2016.

AMERICAN OIL \& GAS HISTORICAL SOCIETY. New London School Explosion. Disponível em: <http://aoghs.org/oil-almanac/new-london-texas-school-explosion/> .Acesso em: 30 jul. 2016.

ATROPEDIA. Ufa train disaster, 2016. Disponível em: $<$ http://en.atropedia.net/article:384fd5>. Acesso em: 30 jul. 2016

BRASIL. Decreto No 7.257, de 4 de agosto de 2010.Regulamenta a Medida Provisória no 494 de 2 de julho de 2010, para dispor sobre o Sistema Nacional de Defesa Civil - SINDEC. Disponível em: <http://www.planalto.gov.br/ccivil_03/_Ato2007-2010/2010/Decreto/D7257.htm\#art17>.Acesso em: 12 mai. 2016.

AGÊNCIA NACIONAL DE ÁGUAS (ANA).Encarte Especial sobre a Bacia do Rio Doce Rompimento

da Barragem em Mariana/MG, 2015. Disponível em: <
http://arquivos.ana.gov.br/RioDoce/EncarteRioDoce_22_03_2016v2.pdf > Acesso em: 30 jul. 2016.

Instituto Brasileiro do Meio Ambiente e dos Recursos Naturais Renováveis (IBAMA). Laudo Técnico Preliminar: impactos ambientais decorrentes do desastre envolvendo o rompimento da barragem de Fundão, em Mariana, Minas Gerais, 2015.2 Disponível em: <http://www.ibama.gov.br/phocadownload/noticias_ambientais/laudo_tecnico_preliminar.pd> Acesso em: 30 jul. 2016.

CARVALHO, Délton Winter de, DAMACENA, Fernanda Dalla Libera. Direito dos Desastres, Porto Alegre: Livraria do Advogado, 2013.

Dano ambiental futuro: a responsabilização civil pelo risco ambiental. Rio de Janeiro: Forense Universitária, 2008.

Por uma necessária introdução ao direito dos desastres ambientais. In:Revista de Direito Ambiental. , São Paulo: RT, ano 17, n. 67, jul.-set., 2012.

CENTRE OF RESEARCH ON THE EPIDEMIOLOGY OF DISASTERS - CRED Annual Disaster Statistical

Review 2012: the numbers and trends, 2012. Disponivel em: <http://cred.be/sites/default/files/ADSR_2012.pdf >.Acesso em: 12 mai. 2016.

COAL INVESTING NEWS. Top 10 Worst Coal Mine Disasters, 2014. Disponível em:<http:// coalinvestingnews.com/17075-top-10-worst-coal-mine-disasters.html >.Acesso em: 12 mai. 2016.

COUNTERSPILL. Cleveland East Ohio gas explosion: abriefhistory, 2011. Disponível em:<http://www.counterspill.org/article\#/article/cleveland-east-ohio-gas-explosion-brief-history>. Acesso em: 20 mai. 2016. 
CRUZ, Euler; CESÁRIO, Rafael. Acidente em Usina Hidrelétrica na Rússia. Disponível em:< http://pt.slideshare.net/Santos63/acidente-em-usina-hidroelectrica-na-russia-2692234>Acesso em: 30 jul. 2016.

DE GIORGI, Raffaele. O risco na sociedade contemporânea. Revista Sequência. n. 28, ano 15, junho, 1994.p. 4554. Disponível em:<http://www.egov.ufsc.br/portal/conteudo/o-risco-na-sociedade-contempor\%C3\%A2nea>. Acesso em:12 mai. 2016.

ENVIRONMENT AND SOCIETY. Expecting Disaster: The 1963 Landslide of the Vajont Dam, 2011. Disponível em: <http://www.environmentandsociety.org/arcadia/expecting-disaster-1963-landslide-vajontdam >. Acesso em: 30 jul. 2016.

EPIC DISASTERS.The ten worst worldwide mining disasters, 2015. Disponível em:<http:/ / epicdisasters.com/the-ten-worst-worldwide-mining-disasters/>. Acesso em: 12 mai. 2016.

GENDISASTERS. Edison, NJ Gas Pipeline Explosion, Mar 1994, 2013 Disponível em:<http://www3.gendisasters.com/new-jersey/19145/edison-nj-gas-pipeline-explosion-mar-1994>. Acesso em: 20 mai. 2016.

Waverly, TN Train Wreck, explosion and fire feb 1978, 2013.Disponível em: $<$ http://www3.gendisasters.com/tennessee/1126/waverly-tn-train-wreck-explosion-fire-feb-1978?pag $\mathrm{e}=0,5>$.Acesso em: 20 mai. 2016 .

GIDDENS, Anthony. A política da mudança climática. Rio de Janeiro: Zahar, 2010.

GOLDEMBERG, José; LUCON, Oswaldo. Energia, meio ambiente e desenvolvimento. 3. ed. ver. ampl. São Paulo: Universidade de São Paulo, 2008.

GREENPEACE. O tamanho do estrago, 2011. Disponível em: $<$ http://www.greenpeace. org/brasil/pt/Noticias/Petroleo-nada-transparente/>. Acesso em: 12 mai. 2016.

HENRICHS, Roger A. Energia e meio ambiente. Tradução técnica Flávio Maron Vichi, Leonardo Freire de Mello. São Paulo: Cengage Learning, 2009.

HYDRONEWS. CleusonDixence. Revista da Andritz, 2010. Disponível em:<http://www.andritz.com/hy-hn17po.pdf>Acesso em: 20 mai. 2016.

INDIA WATERPORTAL. Machhu dam disaster of 1979 in Gujarat - Discussion on a book by Tom Wooten and UtpalSandesara, 2012. Disponível em:<http://www.indiawaterportal.org/articles/machhu-dam-disaster1979-gujarat-discussion-book-tom-wooten-and-utpal-sandesara>.Acesso em: 21 mai. 2016.

INSTITUTO HUMANITAS UNISINOS. Estamos preparados para o pré-sal e o gás de xisto?,2013. Disponível em:<http://www.hu.unisinos.br/noticias/523936-estamos-preparados-para-o-pre-sal-e-o-gas-de-xisto >. Acesso em: 12 mai. 2016.

IO9 WE COME FROM THE FUTURE. Greatest fossil fuel disasters in human, 2010.Disponível em:<http://io9.com/5526826/greatest-fossil-fuel-disasters-in-human-history>. Acesso em: 12 mai. 2016.

LEITE, Antônio Dias. A energia do Brasil. Rio de Janeiro: Nova Fronteira, 1997. 
LUHMANN, Niklas. La sociedad de la sociedade. Tradução Javier Torres Nafarrete. México: Herder/Universidad Iberoamaricana, 2007.

LUHMANN, Niklas. Sociologia del riesgo. México: Herder/Universidad Iberoamaricana, 1992.

MINING - TECNOLOGY. Feature world worst coal mining disaster, 2014.Disponível em:<http://www.mining-technology.com/features/feature-world-worst-coal-mining-disasters-china/>. Acesso em: 12 mai. 2016.

MURTA, Aurélio Lamare Soarés. Energia: o vício da civilização, crise energética e alternativas sustentáveis. Rio de Janeiro: Garamond, 2011.

NEW YORK TIMES.As Turkish Mine Yields the Last Body, Recriminations Remain, 2014. Disponível em:<http://www.nytimes.com/interactive/2014/05/14 /world/europe/mining-explosion-map.html>.Acesso em: 20 mai. 2016.

NGÔ, Cristian. Energia: motor da humanidade. Tradução Constância Egrejas. São Paulo: Senac, 2011.

NIAGARA FALLS INFO. The powerplant. Disponivel em: <http://www.niagarafallsinfo.com/historyitem.php?entry_id=1241\&current_category_id=86>.Acesso em: 12 mai. 2016.

OPERA MUNDI. Hoje na História: 1906 - Explode a mina de Courriéres, na França, 2011. Disponível em: $<$ http://operamundi.uol.com.br/conteudo/noticias/ 102

67/hoje+na+historia

+1906++explode+a+mina+de+courrieres+na+franca.shtml>. Acesso em: 12 mai. 2016.

OUTER SPACE. Explosão da Caldeira de Skikda, 2014. Disponível em:<http://forum.outerspace.com.br/index.php?threads/alguns-do-grandes-erros-desastres-e-trag\%C3 \%A9dias-da-engenharia-na-hist\%C3\%B3ria-fotos-videos.381973/page-3>. Acesso em: 30 jul. 2016

REIS, Lineu Belico dos. Geração de energia elétrica. 2. ed. rev. e atual. São Paulo: Manole, 2011.

REUTERS BRASIL. MPF denuncia Chevron e Transocean por vazamento, 2012. Disponível em:<http://br.reuters.com/article/topNews/idBRSPE82K0A220120321>. Acesso em: 12 mai. 2016.

ROCHA, Leonel Severo. Notas sobre Niklas Luhmann. In: Revista de Estudos Jurídicos. São Leopoldo: Centro de Ciências Jurídicas - UNISINOS, 2007.

SALZMAN, James; THOMPSON JR, Barton H.; DAILY, Gretchen C. Protecting ecosystem services: Science, Economics, and Law. Standford Environmental Law Journal, 2001.

SLUIJS, Jeroen van der; TURKENBURG, Wim. Climate change and the precautionary principle.In: FISHER, Elizabeth; JONES, Judith; SCHOMBERG, René Von. Implementing the precautionary principle, perspectives and prospects.Cheltenham: Edward Elgar, 2006.

SMITH, Denis. In the eyes of the beholder?making sense of the system(s) of disaster(s). In: PERRY, Ronald W. Perry; QUARANTELLI, E.L. What is a disaster? new answers to old questions.EstadosUnidos da América: Xlibris Corporation, 2005. p. 201-236. Disponível em: <http://www.saarcsadkn.org/downloads/what\%20is\%20disaster.pdf>. Acesso em: 15 mai. 2016. 
SOS MATA ATLÂNTICA. Os 10 maiores acidentes petrolíferos da história, 2013. Disponível em: <http://www.sosma.org.br/16659/plano-nacional-contra-vazamentos-de-petroleo-nao-garante-seguranca-dacosta/\#.dpuf>. Acesso em: 20 mai. 2016.

SOUZA FILHO, André Moreira de. Planos Nacionais de Contingência para Atendimento a Derramamento de Óleo: Análise de países representativos das américas para implantação no caso do Brasil. Dissertação em Mestrado. Universidade Federal do Rio de Janeiro, COPPE, 2006. Disponível em: <http://www.ppe.ufrj.br/ppe/production/tesis/amfilho.pdf>Acesso em: 06 jan. 2016.

SUGARMAN, Stephen D. Roles of Government in Compensating. Berkeley: UniversityofCalifornia, 2006. Disponível em: <http://www.law.berkeley.edu/faculty/ sugarmans/Disaster\%20losses\%20ils\%20final.pdf>Acesso em: 12 mai. 2016.

SYLVESTER, Arthur Gibbs. Teton dam failure. Department of Earth Science University of California Santa Barbara, CA 93106-9630. Disponível em:<http://www.geol. ucsb.edu/faculty/sylvester/Teton_Dam/welcome_dam.html>.Acesso em: 21 mai. 2016.

THE INTERNATIONAL ENERGY AGENCY - Implementing Agreement for Hydropower Technologies And Programmes. Environmental and health impacts of electricity generation: A comparison of the environmental impacts of hydropower with those of other generation technologies, 2002. Disponível em: <http://www.ieahydro.org/media/b9067994/A\%20Comparison\%20of\%20the\%20Environmental\%20Impacts \%20 of\%20Hydropower\%20with\%20those\%20of\%20Other\%20Generation\%20Technologies\%20.pdf >Acesso em: 30 jul. 2016.

THE INTERNATIONAL NUCLEAR AND RADIOLOGICAL EVENT SCALE, 2008. Disponível em:<http://www.iaea.org/Publications/Factsheets/English/ines.pdf>. Acesso em: 12 mai. 2016.

UNIVERSAL ROVER. Top 10 worst industrial disaster over the globe, 2013. Disponível em:<http://universalrover.wordpress.com/2013/07/31/top-10-worst-industrial-disaster-over-the-globe/>.

Acesso em: 30 jul. 2016.

URRY, J. Global Complexity. Cambridge: Polity Press. In: SMITH, Denis. In the eyes of the beholder?making sense of the system(s) of disaster(s). In: PERRY, Ronald W. Perry; QUARANTELLI, E.L. What is a disaster? new answers to old questions. Estados Unidos da América: Xlibris Corporation, 2005. p. 201-236. Disponível em:<http://www.saarc-sadkn.org/downloads/what\%20is\%20disaster.pdf >. Acesso em: 15 mai. 2016.

Trabalho enviado em 29 de maio de 2016.

Aceito em 31 de agosto de 2016. 